\title{
INVENTORY DAN TRANSPORTASI PADA JARINGAN BERKENDALA MENGGUNAKAN SIMULTANEOUS OPTIMIZATION METHOD
}

\author{
Wahyu Sri Utami ${ }^{i}$
}

${ }^{i}$ ProdiTeknik Informatika, Universitas Teknologi Yogyakarta,wahyu.utami@uty.ac.id

\begin{abstract}
ABSTRAK, Perlakuan terhadap material mulai dari titik produksi (source) sampai sebagai produk di titik konsumsi (sink) jika tidak dikelola secara profesional biasanya akan memerlukan biaya yang relatif cukup tinggi bagi perusahaan. Hal ini merupakan masalah yang krusial untuk diselesaikan. Permasalahan yang ditimbulkan pada dasarnya adalah kombinasi dari permasalahan produksi, transportasi dan bagaimana menentukan order yang ekonomis. Secara tradisional tahap-tahap dalam pemrosesan material tersebut dioptimasi secara terpisah. Akan tetapi, semakin banyak titik sumber dan titik tujuan, maka tidak akan praktis lagi jika harus dioptimasi terpisah. Sehingga dalam penelitian ini digunakan metode optimasi simultan yang mengintegrasikan seluruh proses tersebut kedalam suatu bentuk model logistik yang tidak linear kemudian akan dioptimasi secara simultan. Fungsi objektifnya adalah meminimalkan total biaya inventory, produksi dan transportasi dengan kendala terbatasnya stok persediaan dan permintaan yang harus terpenuhi. Hasil yang diperoleh menunjukkan bahwa dengan menggunakan optimasi simultan, biaya yang dikeluarkan lebih rendah dibandingkan jika menggunakan metode optimasi secara tradisional.
\end{abstract}

Kata Kunci: inventory, produksi, transportasi, order, metode optimasi terpisah, metode optimasi simultan

\section{PENDAHULUAN}

Metode riset operasi (operation research) yang pada prinsipnya berisi berbagai tehnik kuantitatif yang banyak dipakai dalam pengambilanpengambilan keputusan manajemen (Pangestu Subagyo, 1992). Permasalahan peminimalan biaya pada jaringan rantai persediaan, dimana untuk meminimalkan biaya inventory, produksi dan transportasi secara tradisional dihitung (dioptimasi) secara terpisah (Julian Benjamin, 1989). Pemrosesannya dimulai dari produksi di titik source, kemudian disimpan sebagai persediaan sampai sikirimkan ke titik sink. Permasalahan yang mempunyai lebih banyak sumber dan tujuan akan menjadi tidak efisien jika dikerjakan secara terpisah, sehingga pada penelitian ini penulis ingin menggunakan suatu metode efektif untuk menyelesaikan permasalahan tersebut secara keseluruhan yang disebut simultaneous optimization method (Julian Benjamin, 1989), dan kemudian membandingkan solusi yang diperoleh dari metode tersebut dengan solusi yang diperoleh dari metode optimasi secara terpisah maupun konvensional.

\section{TINJAUAN PUSTAKA}

Persoalan utama dalam pengelolaan persediaan ini terkandung dalam dua pertanyaan utama, yaitu: berapa banyak harus disediakan dan kapan penyediaan itu dilakukan. (Imam K., 2003). Permasalahan yang diangkat dalam penelitian ini adalah berapa banyaknya barang yang harus di produksi dan di order agar total biaya yang dikeluarkan mulai dari titik source sampai titik sink menjadi minimum.

Permasalahan dirumuskan kedalam model persediaan independen, yaitu model dengan penentuan jumlah pembelian bahan atau barang yang bersifat bebas. Biasanya diaplikasikan untuk pembelian persediaan di mana permintaannya bersifat kontinyu dari waktu ke waktu dan konstan sehingga hanya ada beberapa model inventory yang sesuai dan memenuhi kondisi tersebut, yaitu:

\section{1) Economic Order Quantity (EOQ) \\ 2) Economic Production Quantity (EPQ) \\ 3) The Quantity Discount Model}

Karena diasumsikan tidak ada diskon, sehingga hanya model 1 dan 2 yang akan digunakan guna menyelesaikan permasalahan dalam penelitian ini. 


\section{MODEL ECONOMIC ORDER QUANTITY (EOQ)}

Total biaya tahunan (total annual cost) untuk model EOQ berasal dari holding cost ditambah dengan order cost.

$T C=\frac{1}{2} \sqrt{2 D O H}+\sqrt{\frac{H D O}{2}}$

dimana,

$\mathrm{TC}=$ total cost

$\mathrm{H}=$ holding cost per unit

$\mathrm{D}=$ total permintaan $($ demand $)$ per satuan waktu

$\mathrm{O}=$ order cost per order

\section{MODEL ECONOMIC PRODUCTION QUANTITY (EPQ)}

Sedangkan total biaya untuk model EPQ diperoleh dari penjumlahan holding cost dengan set up cost.

$T C=\frac{1}{2} \sqrt{\frac{2 D S P}{(P D) H}} 1 \frac{D}{P} \div H+\sqrt{\frac{(P D) H}{2 D S P}} D S$

dimana,

$\mathrm{TC}=$ total cost

$\mathrm{H} \quad=$ holding cost per unit

$\mathrm{D}=$ total permintaan (demand) per satuan waktu

$\mathrm{P} \quad=$ laju produksi per satuan waktu

$\mathrm{S} \quad=$ set-up cost per unit

\section{MODEL BIAYA TRANSPORTASI}

Secara umum permasalahan transportasi disumuskan menjadi model transportation cost sebagai berikut :

$$
\text { Transportation } \cos t={ }_{i=1}^{m} C_{i j} X_{i j}
$$

Dengan $\mathrm{C}_{\mathrm{ij}}$ biaya transport per unit barang yang dkirimkan dari titik source $\mathrm{i}$ ke titk sink $\mathrm{j}$ dan $\mathrm{X}_{\mathrm{ij}}$ adalah banyaknya unit barang yang dkirimkan dari titik source i ke titk sink $\mathrm{j}$. (Wayne $\mathrm{L}$. Winston, 1994)

\section{METODOLOGI}

Proses yang dilakukan dalam penelitian ini dilakukan dengan urutan sebagai berikut:

1. Membentuk model total logistic problem mulai di titik source sampai ke titik sink.

2. Mencari solusi optimal menggunakan metode konvensional atau traditional optimization method.

3. Mencari solusi optimal menggunakan metode heuristik (Julian Benjamin, 1989) untuk problem multi source dan multi sink.

4. Untuk memperjelas hasil yang diperoleh dalam pembahasan diberikan simulasi numeric dan digunakan software LINGO untuk mempermudah penyelesaian dalam penentukan solusi terbaik dari tiap-tiap metode.

\section{PEMBAHASAN}

\section{MEMBENTUK MODEL LOGISTIC PROBLEM}

Total biaya di titik source adalah hasil penjumlahan biaya produksi, holding costs dan set-up cost menjadi persamaan berikut ini:

$$
\begin{array}{r}
f_{1}\left(z_{1}, \ldots \ldots, z_{m}, X_{11}, \ldots \ldots, X_{m n}\right) \\
={ }^{m} \quad \begin{array}{lll}
r_{i} S_{i}+\frac{z_{i}}{2} 1 & \frac{S_{i}}{P_{i}} \div H_{i}+ & \div \\
{ }_{i=1} & \frac{S_{i}}{z_{i}} K_{i}+\frac{H_{i}}{2}{ }_{j=1}^{n} X_{i j} & \stackrel{\doteqdot}{\doteqdot}
\end{array}
\end{array}
$$

dimana,

$f_{1}=$ total biaya di titik source

$r_{i}=$ biaya produksi per unit di titik produksi i

$\mathrm{S}_{\mathrm{i}}=$ kapasitas produksi tahunan di titik source i, ditentukan terlebih dahulu untuk analisis

$\mathrm{H}_{\mathrm{i}}=$ holding cost di titik source $\mathrm{i}$

$\mathrm{P}_{\mathrm{i}}=$ laju produksi tahunan di titik source i 
$\mathrm{Z}_{\mathrm{i}}=$ jumlah produksi di titik

produksi i

$\mathrm{K}_{\mathrm{i}}=$ set up cost di titik produksi $\mathrm{i}$

$\mathrm{X}_{\mathrm{ij}}=$ jumlah unit barang yang akan

dikirim dari titik source i ke

titik sink j per order

Biaya transportasi merupakan suatu bentuk fungsi persamaan linear sebagai berikut:

$$
f_{2}\left(Y_{11}, \ldots \ldots \ldots . ., Y_{m n}\right)={ }_{i=1}^{m}{ }_{j=1}^{n} C_{i j} Y_{i j}
$$

dimana,

$f_{2}=$ total biaya transportasi

$\mathrm{C}_{\mathrm{ij}}=$ biaya transportasi per unit dari titik source i ke titik sink j

$Y_{i j}=$ jumlah unit yang akan dikirim dari titik source i ke titik sink j per tahun.

Karena tidak ada proses produksi, maka total biaya di titik sink hanya memuat biaya inventory saja. Biaya inventory di titik sink dirumuskan sebagai persamaan berikut

$$
\begin{aligned}
& f_{3}\left(X_{11}, \ldots \ldots, X_{m n}, Y_{11}, \ldots \ldots, Y_{m n}\right) \\
& ={ }_{i=1}^{m}{ }_{j=1}^{n} \frac{X_{i j}}{2} G_{j}+\frac{Y_{i j}}{\left(0,001+X_{i j}\right)} I_{j} \doteqdot
\end{aligned}
$$

dimana,

$f_{3}=$ total biaya di titik sink

$\mathrm{G}_{\mathrm{j}}=$ holding cost di titik sink $\mathrm{j}$

$\mathrm{I}_{\mathrm{j}} \quad=$ order cost di titik $\sin k \mathrm{j}$

$\mathrm{X}_{\mathrm{ij}}=$ jumlah unit barang yang akan

dikirim dari titik source i ke

titik sink j per order

$Y_{i j}=$ jumlah unit yang akan dikirim

dari titik source i ke titik sink j

per tahun.

Sehingga total biaya keseluruhan proses mulai dari titik source sampai titik sink dirumuskan menjadi persamaan berikut:

$$
\begin{aligned}
W= & f_{1}(z, X)+f_{2}(Y)+f_{3}(X, Y) \\
= & \sum_{i=1}^{m}\left(r_{i} S_{i}+\frac{z_{i}}{2}\left(1-\frac{S_{i}}{P_{i}}\right) H_{i}+\frac{S_{i}}{z_{i}} K_{i}+\frac{H_{i}}{2} \sum_{j=1}^{n} X_{i j}\right)+\sum_{i=1}^{m} \sum_{j=1}^{n} C_{i j} Y_{i j}+ \\
& \sum_{i=1}^{m} \sum_{j=1}^{n}\left(\frac{X_{i j}}{2} G_{j}+\frac{Y_{i j}}{\left(0,001+X_{i j}\right)} I_{j}\right)
\end{aligned}
$$

Fungsi biaya 4.4 merupakan total model logistic problem yang akan diminimalkan. Apabila kapasitas supply yang terbatas dan permintaan yang harus dipenuhi diperhitungkan, maka formulasi problem menjadi:

\section{Minimize $_{z_{1}, X_{i j}, Y_{i j}}$}

$W=\sum_{i=1}^{m}\left(r_{i} S_{i}+\frac{z_{i}}{2}\left(1-\frac{S_{i}}{P_{i}}\right) H_{i}+\frac{S_{i}}{z_{i}} K_{i}+\frac{H_{i}}{2} \sum_{j=1}^{n} X_{i j}\right)+$
$\sum_{i=1}^{m} \sum_{j=1}^{n} C_{i j} Y_{i j}+\sum_{i=1}^{m} \sum_{j=1}^{n}\left(\frac{X_{i j}}{2} G_{j}+\frac{Y_{i j}}{\left(0,001+X_{i j}\right)} I_{j}\right)$

Subject to $: \sum_{i=1}^{m} Y_{i j}=D_{j}$,

$$
\sum_{j=1}^{n} Y_{i j}=S_{i}
$$

$0 \leq \mathrm{z}_{\mathrm{i}} \leq \mathrm{S}_{\mathrm{i}}$ untuk setiap $\mathrm{i} ; 0 \leq \mathrm{X}_{\mathrm{ij}} \leq \mathrm{Y}_{\mathrm{ij}}$ untuk setiap i dan $\mathrm{j}$;

$$
{ }_{i=1}^{m} S_{i}={ }_{j=1}^{n} D_{j}
$$

dimana ,

$\mathrm{D}_{\mathrm{j}}=$ permintaan tahunan di titik $\operatorname{sink} \mathrm{j}$

$\mathrm{S}_{i}=$ kapasitas produksi tahunan di titik source

Baik $D_{j}$ dan $S_{j}$ keduanya di tentukan terlebih dahulu untuk analisis.

Menentukan Solusi Optimum untuk Problem Produksi-Transportasi-Inventory pada Sistem Multi Source dan Multi Sink Menggunakan Metode Konvensional.

Perhitungan untuk problem ini telah mencakup pembahasan pada problem satu source satu sink. Akan dihitung total biaya yang dikeluarkan 
untuk proses produksi di titik source i (i $=1,2,3, \ldots \mathrm{m})$, biaya transportasi dan biaya di titik $\operatorname{sink} \mathrm{j}(\mathrm{j}=1,2,3, \ldots \mathrm{n})$.

Total cost optimum sementara di titik source adalah:

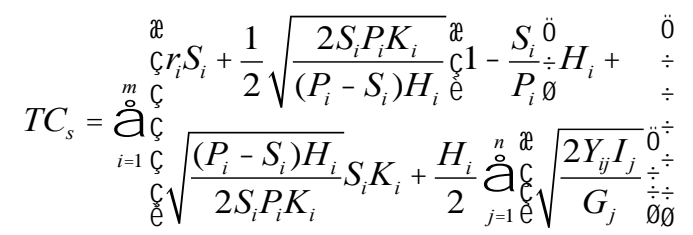

Untuk mencari biaya pendistribusian barang dari tiap-tiap titik source ke tiap-tiap titik sink digunakan rumus transportation cost yang sama dengan persamaan (3.16) yaitu:

$$
\begin{gathered}
\text { Total transportation } \cos t=\sum_{i=1}^{m} \sum_{j=1}^{n} C_{i j} Y_{i j} \\
\forall_{i}, i=1,2, \ldots m \\
{ }_{j}, j=1,2, \ldots n
\end{gathered}
$$

Total cost minimum di titik sink diperoleh rumus sebagai berikut:

$$
T C_{k}=\sum_{i=1}^{m} \sum_{j=1}^{n}\left(\frac{G_{j}}{2}\left(\sqrt{\frac{2 Y_{i j} I_{j}}{G_{j}}}\right)+\frac{Y_{i j} I_{j}}{0,001+\sqrt{\frac{2 Y_{i j} I_{j}}{G_{j}}}}\right)
$$

Untuk memperoleh total biaya mulai dari titik sink sampai ke titik source, dihitung dengan menjumlahkan solusi-solusi yang telah diperoleh di tiap-tiap titik. Total biaya keseluruhan terdiri dari total biaya di titik source, total biaya transportasi, dan total biaya di titik sink. Sehingga total biaya keseluruhan dapat dituliskan oleh persamaan berikut ini:

Total $\cos t=T C_{S}+$ Transportation Cost $+T C_{K}$

$$
\begin{aligned}
& \text { Total cost }={ }^{m} r_{i} S_{i}+\frac{1}{2} \sqrt{\frac{2 S_{i} P_{i} K_{i}}{\left(P_{i} S_{i}\right) H_{i}}} 1 \frac{S_{i}}{P_{i}} \div H_{i}+\frac{\dot{亠}}{\grave{\vdots}} \\
& \text { i=1 } \sqrt{\frac{\left(P_{i} S_{i}\right) H_{i}}{2 S_{i} P_{i} K_{i}}} S_{i} K_{i}+\frac{H_{i}}{2}{ }_{j=1}^{n} \sqrt{\frac{2 Y_{i j} I_{j}}{G_{j}}} \dot{\doteqdot} \dot{\doteqdot} \dot{\doteqdot}
\end{aligned}
$$

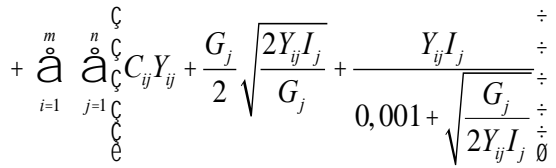

Persamaan 4.1.4 adalah persamaan multi variabel, sehingga dengan menyederhanakan persamaan tersebut, diperoleh persamaan yang meminimalkan biaya dengan kendala kapasitas supply yang terbatas dan permintaan yang harus dipenuhi.

Minimize

$$
\begin{array}{r}
=\sum_{i=1}^{m}\left(r_{i} S_{i}+2 \sqrt{\frac{\left(P_{i}-S_{i}\right) S_{i} K_{i} H_{i}}{2 P_{i}}}+\frac{H_{i}}{2} \sum_{j=1}^{n}\left(\sqrt{\frac{2 Y_{i j} I_{j}}{G_{j}}}\right)\right)+ \\
\sum_{i=1}^{m} \sum_{j=1}^{n}\left(C_{i j} Y_{i j}+\frac{G_{j}}{2} \sqrt{\frac{2 Y_{i j} I_{i j}}{G_{j}}}+\frac{Y_{i j} I_{j}}{0,001+\sqrt{\frac{G_{j}}{2 Y_{i j} I_{j}}}}\right)
\end{array}
$$

$$
\text { Subject to : } \begin{aligned}
\sum_{i=1}^{m} Y_{i j} & =D_{j^{\prime}}, \\
\sum_{j=1}^{n} Y_{i j} & =S_{i},
\end{aligned}
$$

$0 \leq \mathrm{Z}_{\mathrm{i}} \leq \mathrm{S}_{\mathrm{i}}$ untuk setiap $\mathrm{i} ; 0 \leq \mathrm{X}_{\mathrm{ij}} \leq \mathrm{Y}_{\mathrm{ij}}$ untuk setiap $\mathrm{i}$ dan $\mathrm{j} ; \sum \mathrm{S}_{\mathrm{i}}=\sum \mathrm{D}_{\mathrm{j}}$.

Untuk menyelesaikan bentuk persamaan dengan kendala seperti persamaan diatas pada dasarnya dapat diselesaikan secara manual menggunakan metode pengali Lagrange. Akan tetapi untuk permasalahan multi source dan multi sink yang lebih besar, tidak memungkinkan lagi jika harus diselesaikan secara manual, sehingga digunakan software Lingo untuk mempermudah mendapatkan solusi.

Menentukan Solusi Optimum untuk Problem Produksi-Transportasi-Inventory pada Sistem Multi Source dan Multi Sink Menggunakan Metode Optimasi Simultan dengan Heuristik.

Pada penelitian ini, untuk menyelesaikan problem produksi-transportasi-inventory multi source dan multi sink digunakan metode simultan Heuristic (Julian Benjamin, 1989). Pada metode ini, fungsi objektif dan kendala pada persamaan 4.1.5 akan diselesaikan secara simultan dengan terlebih dahulu mengoptimasi variabel $z_{i}$ dan variabel $\mathrm{X}_{\mathrm{ij}}$ pada persamaan $\mathrm{W}$. Dan hanya pada persaman $\mathrm{W}$ yang terdiri dari variabel-variabel $X_{i j}$ dan $Y_{i j}$ tersebut yang kemudian akan dioptimasi bersama secara heuristik. Metode ini disebut sebagai Simultaneous Solution Procedures. 


$$
\begin{aligned}
& W={ }_{i=1}^{m} \quad r_{i} S_{i}+\frac{z_{i}}{2} 1 \frac{S_{i}}{P_{i}} \div H_{i}+\frac{S_{i}}{z_{i}} K_{i}+\frac{H_{i}}{2}{ }_{j=1}^{n} X_{i j} \dot{\dot{\div}}+ \\
& { }_{i=1}^{m}{ }_{j=1}^{n} C_{i j} Y_{i j}+{ }_{i=1}^{m}{ }_{j=1}^{n}\left(\frac{X_{i j}}{2} G_{j}+\frac{Y_{i j}}{\left(0,001+X_{i j}\right)} I_{j}\right)
\end{aligned}
$$

Variabel $\mathrm{z}_{\mathrm{i}}$ dihitung terpisah dari persamaan $\mathrm{W}$ dan kemudian diselesaikan menggunakan optimasi klasik sebagai suatu bentuk fungsi Economic Production Lot Size Problem dan diperoleh solusi untuk $\mathrm{Z}_{\mathrm{i}}$ adalah sebagai berikut:

$$
\begin{array}{ll}
\frac{\partial W}{\partial z_{i}}=0, & \forall_{i}, i=1,2, \ldots m \\
\frac{1}{2} 1 \quad \frac{S_{i}}{P_{i}} \div H_{i} \quad \frac{S_{i}}{z_{i}^{2}} K_{i}=0 & \forall_{i}, i=1,2, \ldots m \\
z_{i}=\sqrt{\frac{2 S_{i} P_{i} K_{i}}{\left(P_{i} S_{i}\right) H_{i}}} \quad, \quad \forall_{i}, i=1,2, \ldots m
\end{array}
$$

$\mathrm{Z}_{\mathrm{i}}$ adalah banyaknya barang yang harus diproduksi di titik source i agar biaya yang dikeluarkan oleh perusahaan minimum.

Kemudian mendefferensial-kan $\mathrm{W}$ terhadap $\mathrm{X}_{\mathrm{ij}}$ secara terpisah dan menyamadengankan nol, akan diperoleh solusi untuk $\mathrm{X}_{\mathrm{ij}}$.

$$
\begin{aligned}
& W={ }_{i=1}^{m}\left(r_{i} S_{i}+\frac{z_{i}}{2} 1 \frac{S_{i}}{P_{i}} \div H_{i}+\frac{S_{i}}{z_{i}} K_{i}+\frac{H_{i}}{2}{ }_{j=1}^{n} X_{i j}\right)+ \\
& { }_{i=1}^{m}{ }_{j=1}^{n} C_{i j} Y_{i j}+{ }_{i=1}^{m} \quad{ }_{j=1}^{n}\left(\frac{X_{i j}}{2} G_{j}+\frac{Y_{i j}}{\left(0,001+X_{i j}\right)} I_{j}\right)
\end{aligned}
$$

Dengan menggunakan metode optimasi klasik untuk mendapatkan $\mathrm{X}_{\mathrm{ij}}$.

$$
\begin{aligned}
& \frac{\partial W}{\partial X_{i j}}=0 \quad \forall_{i}, i=1,2, . . m, \forall_{j}, j=1,2, . . n \\
& \frac{H_{i}}{2}+\frac{G_{j}}{2}-\frac{I_{j} Y_{i j}}{\left(0,001+X_{i j}{ }^{2}\right)}=0 \quad \forall_{i}, i=1,2, \ldots m, \forall_{j}, j=1,2, \ldots n
\end{aligned}
$$

Maka diperoleh solusi untuk $\mathrm{X}_{\mathrm{ij}}$ sebagai berikut:

$$
X_{i j}=\sqrt{\frac{2 I_{j} Y_{i j}}{\left(G_{j}+H_{i}\right)}}-0,001 \quad \forall_{i}, i=1,2, . . m,
$$

$$
\forall_{j}, j=1,2, \ldots n
$$

Pada persamaan 4.2.5, jika $\mathrm{Y}_{\mathrm{ij}}$ bernilai nol (tidak terjadi pengiriman), maka pastinya $\mathrm{X}_{\mathrm{ij}}$ juga bernilai nol (tidak terjadi order). Akan tetapi karena terjadi pengurangan 0,001 maka nilai $\mathrm{X}_{\mathrm{ij}}$ yang diperoleh pada persamaan akan bernilai negatif dan solusi menjadi tidak terdefinisi. Sehingga persamaan untuk mendapatkan nila $X_{i j}$ yang positif adalah tanpa pengurangan 0,001 . Maka diperoleh solusi untuk $\mathrm{X}_{\mathrm{ij}}$ sebagai berikut:

$$
\begin{aligned}
& X_{i j}=\sqrt{\frac{2 I_{j} Y_{i j}}{\left(G_{j}+H_{i}\right)}} \\
& \forall_{i}, i=1,2, \ldots m, \quad \forall_{j}, j=1,2, \ldots n
\end{aligned}
$$

$\mathrm{X}_{\mathrm{ij}}$ adalah batas bawah awal yang akan digunakan untuk menemukan solusi akhir.

Fungsi objektif $\mathrm{W}$ menjadi suatu bentuk fungsi linear terhadap $\mathrm{Y}_{\mathrm{ij}}$.

Solusi optimum untuk $Y_{\mathrm{ij}}$ dapat diperoleh dengan menyelesaikan program linear pada persamaan berikut.

$$
\begin{array}{rlrl}
\text { Minimize } & W^{\prime}=\sum_{i=1}^{m} \sum_{j=1}^{n} A_{i j} Y_{i j} \\
\text { subject to }: \sum_{i=1}^{m} Y_{i j} & =D_{j} & \forall_{i}, i=1,2, \ldots m \\
\sum_{j=1}^{n} Y_{i j} & =S_{i} & \forall_{j}, j=1,2, \ldots n
\end{array}
$$

Dimana koefisian A pada persamaan diatas adalah:

$$
\begin{gathered}
A_{i j}=\left(C_{i j}+\frac{I_{j}}{\left(0,001+X_{i j}\right)}\right), \\
\forall_{i}, i=1,2, \ldots m
\end{gathered}
$$

Pada' $\stackrel{\forall}{j=1,2, \ldots n}$ persamaan 4.2 .8 variabel $\mathrm{X}_{\mathrm{ij}}$ ditambah dengan 0,001 agar tidak terjadi pembagian dengan nol jika $\mathrm{X}_{\mathrm{ij}}$ bernilai nol.

Sehingga persamaan (4.2.8) adalah meminimumkan fungsi $W^{\prime}$ pada saat $\mathrm{A}_{\mathrm{ij}}$ 
disubstitusi. Diperoleh biaya optimumnya sebagai berikut:

$$
\mathrm{W}^{*}=f_{1}+W^{\prime}
$$

Solusi-solusi yang telah diperoleh pada persamaan diatas, belum cukup untuk menyelesaikan Simultaneous Solution Procedures. Untuk memperoleh solusi akhir yang optimum, digunakan algoritma yang dianggap efisien dan solusi yang diperoleh mendekati nilai optimum sebenarnya. Dalam Tugas Akhir ini, penulis menggunakan metode Heuristic (Julian Benjamin, 1989) untuk menyelesaikan permasalahan yang ada. Metode ini akan menggabungkan solusi-solusi yang telah diperoleh pada persamaan (4.2.6), (4.2.7), dan (4.2.8) untuk mencari solusi akhirnya.

Langkah - langkah dalam metode heuristic adalah sebagai berikut:

1. Menentukan solusi untuk $\mathrm{Z}_{\mathrm{i}}$ yang telah dihitung pada persamaan (4.2.2).

2. Menentukan solusi fesibel awal untuk $Y_{i j}$ dengan mencari nilai minimum dari $S_{i}$ dan $D_{j}, Y_{i j}{ }^{0}=\operatorname{Minimum}\left[S_{i}, D_{j}\right]$. Ambil nilai awal $\mathrm{t}=0$

a. Mensubstitusi $\mathrm{Y}_{\mathrm{ij}}^{\mathrm{t}}$ ke persamaan (4.2.5) dan diperoleh nilai awal untuk $\mathrm{X}_{\mathrm{ij}}{ }^{\mathrm{t}}$.

b. Menentukan solusi fesibel lokal optimum dengan langkah - langkah sebagai berkut:

1. Menghitung nilai untuk koefisien $\mathrm{A}_{\mathrm{ij}}{ }^{\mathrm{t}}$ dengan mensubstitusi $\mathrm{X}_{\mathrm{ij}}{ }^{\mathrm{t}} \mathrm{ke}$ persamaan (4.2.8).

2. Menentukan solusi fesibel baru $\mathrm{Y}_{\mathrm{ij}}{ }^{\mathrm{t}+1}$ dengan mensubstitusi $\mathrm{A}_{\mathrm{ij}}{ }^{\mathrm{t}}$ kedalam persamaan (4.1.5) dan menyelesaikannya sebagai suatu bentuk pemrograman linear.

3. Menghitung $\mathrm{X}_{\mathrm{ij}}^{\mathrm{t}+1}$ dengan mensubstitusi $\mathrm{Y}_{\mathrm{ij}}^{\mathrm{t}}{ }^{\mathrm{t}+1}$ ke persamaan (4.2.5).

4. Menentukan nilai dari fungsi objektif yang baru $\mathrm{W}^{\mathrm{t}+1}$ dengan mensubstitusi $\mathrm{Z}_{\mathrm{i}}, \mathrm{X}_{\mathrm{ij}}^{\mathrm{t}}{ }^{\mathrm{t}}$, dan $\mathrm{Y}_{\mathrm{ij}}^{\mathrm{t}+1}$ kedalam persaman (4.2.1). c. Stop iterasi jika $\mathrm{Y}_{\mathrm{ij}}^{\mathrm{t}+1}=\mathrm{Y}_{\mathrm{ij}}^{\mathrm{t}}$. Jika tidak ambil $\mathrm{t}=\mathrm{t}+1$ kemudian kembali ke langkah no $2 b$.

3. $\mathrm{W}^{*}=$ Minimum $\left[\mathrm{W}^{\mathrm{t}}\right]$.

Untuk mengaplikasikan algoritma diatas, dapat dikerjakan secara manual. Akan tetapi untuk permasalahan yang semakin banyaknya titik source dan titik sink, maka tidak akan praktis lagi jika harus dikerjakan secara manual. Sehingga dalam pengerjaan tugas akhir ini penulis menggunakan software LINGO untuk mempermudah pengerjaannya. LINGO adalah suatu software yang dapat menyelesaikan permasalahan optimisasi yang berbentuk persamaan linear maupun non linear. LINGO memperingkas pengerjaan suatu problem pemrograman linear maupun nonlinear, dengan memasukkan model tersebut kemudian menyelesaikannya sampai diperoleh solusi optimum, dan menganalisa hasil optimum tersebut. Untuk lebih memahami tentang kegunaan LINGO, diberikan contoh dengan bentuk permasalahan multi source dan multi sink.

\section{Contoh Problem multi source dan multi sink}

Diberikan 3 anak perusahaan yang memproduksi satu jenis item dan 4 distributor yang akan menerima item dari tiap-tiap perusahaan penyuplai. Diketahui biaya produksi per unit di masing-masing titik produksi adalah $\left(\mathrm{r}_{\mathrm{i}}\right), \mathrm{r}_{1}=\$ 5$, $r_{2}=\$ 3, r_{3}=\$ 6$. Laju produksi tahunan untuk masing-masing titik source adalah: $\mathrm{P}_{1}=38000$, $\mathrm{P}_{2}=37700, \quad \mathrm{P}_{3}=59000$. Besarnya demand, suppply, biaya inventory dan biaya transportasi diberikan pada tabel-tabel diawah ini.

Tabel 1. Biaya transportasi (\$/unit) dari titik source (i) ke titik sink (j)

\begin{tabular}{c|c|c|c|c}
\hline \multirow{2}{*}{ Source $(i)$} & \multicolumn{4}{|c}{$\operatorname{Sink}(j)$} \\
\cline { 2 - 5 } & $\mathrm{A}$ & $\mathrm{B}$ & $\mathrm{C}$ & $\mathrm{D}$ \\
\hline I & 1,33 & 0,69 & 0,53 & - \\
II & 0,98 & 1,23 & 1,68 & - \\
III & - & - & 1,13 & 0,30 \\
\hline
\end{tabular}

Tabel 2. Kapasitas tahunan dan biaya inventory di titik source

$$
\text { Parameter }
$$




\begin{tabular}{l|c|c|c}
\hline $\begin{array}{l}\text { Kapasitas } \\
\text { tahunan } \\
\text { (unit/tahun) }\end{array}$ & 37000 & 37000 & 58000 \\
$\begin{array}{l}\text { Set up cost } \\
\text { (\$/produksi) }\end{array}$ & 5000 & 5000 & 5000 \\
$\begin{array}{l}\text { Holding cost } \\
\text { (\$/unit/tahun) }\end{array}$ & 0,10 & 0,10 & 0,10 \\
\hline
\end{tabular}

Tabel 3. Permintaan tahunan dan biaya inventory di titik sink

\begin{tabular}{l|c|c|c|c}
\hline \multicolumn{1}{c|}{ Parameter } & A & B & C & D \\
\hline $\begin{array}{l}\text { Permintaan } \\
\text { tahunan } \\
\text { (unit/tahun) }\end{array}$ & 12000 & 9000 & 109000 & 2000 \\
$\begin{array}{l}\text { Order cost } \\
\text { (\$/order) }\end{array}$ & 20 & 20 & 20 & 20 \\
$\begin{array}{l}\text { Holding cost } \\
\text { (\$//unit/tahun) }\end{array}$ & 0,12 & 0,12 & 0,12 & 0,12 \\
\hline
\end{tabular}

Perusahaan ingin menghitung besarnya produksi barang dan besarnya order yang harus dikirim dari tiap-tiap titik source i ke tiap-tiap titik sink j tiap tahunnya agar biaya yang dikeluarkan minimum serta banyaknya order dalam setahun yang harus dipenuhi.

\section{Penyelesaian menggunakan konvensional.}

metode

Diperoleh jumlah barang yang harus diproduksi di masing-masing titik source i adalah:

$$
\begin{aligned}
& z_{1}=\sqrt{\frac{2 \times 37000 \times 38000 \times 5000}{(3800037000) \times 0,1}} \quad 374967 \\
& z_{2}=\sqrt{\frac{2 \times 37000 \times 37700 \times 5000}{(3770037000) \times 0,1}} \quad 446398 \\
& z_{3}=\sqrt{\frac{2 \times 58000 \times 59000 \times 5000}{(5900058000) \times 0,1}} \quad 584979
\end{aligned}
$$

Dimana $Z_{i}$ adalah banyaknya barang yang harus diproduksi di titik source i agar biaya produksi yang dikeluarkan oleh perusahaan menjadi minimum.

Solusi $\mathrm{Y}_{\mathrm{ij}}$ akan dicari menggunakan software LINGO, diperoleh:
$\mathrm{Y}_{11}=0 \quad \mathrm{Y}_{23}=16000$

$\mathrm{Y}_{12}=0 \quad \mathrm{Y}_{24}=0$

$\mathrm{Y}_{13}=37000 \quad \mathrm{Y}_{31}=0$

$\mathrm{Y}_{14}=0 \quad \mathrm{Y}_{32}=0$

$\mathrm{Y}_{21}=12000 \quad \mathrm{Y}_{33}=56000$

$\mathrm{Y}_{22}=9000 \quad \mathrm{Y}_{34}=2000$

Dengan menggunakan LINGO diperoleh output total biaya optimumnya adalah \$ 782504,5. Selanjutnya dihitung nilai $\mathrm{X}_{\mathrm{ij}}$ yaitu jumlah barang yang di order dari titik source i ke titik sink $\mathrm{j}$ dengan mensubstitusi $\mathrm{Y}_{\mathrm{ij}}$ yang telah diperoleh sebelumnya. Sedangkan dengan menggunakan metode konvensional, diperoleh biaya minimum yang harus dikeluarkan oleh perusahaan sebesar $\$ 782504,5$ dimana order optimumnya adalah $\mathrm{X}_{\mathrm{ij}}$ dan jumlah barang yang harus dikirim per tahunnya adalah $\mathrm{Y}_{\mathrm{ij}}$.

\section{Penyelesaian problem multi source dan multi sink menggunakan metode heuristik.}

Persoalan akan diselesaikan sesuai metode heuristik (Julian Benjamin, 1989), dengan langkah-langkah sebagai berikut:

1. Menghitung nilai $\mathrm{z}_{\mathrm{i}}$.

$$
\begin{aligned}
& z_{i}=\sqrt{\frac{2 S_{i} P_{i} K_{i}}{\left(P_{i}-S_{i}\right) H_{i}} \quad \forall_{i}, i}=1,2,3 \\
& z_{1}=\sqrt{\frac{2 \times 37000 \times 38000 \times 5000}{(38000-37000) \times 0,1}}=374966,7 \\
& z_{2}=\sqrt{\frac{2 \times 37000 \times 37700 \times 5000}{(37700-37000) x 0,1}}=446398,3 \\
& z_{3}=\sqrt{\frac{2 \times 58000 \times 59000 \times 5000}{(59000-58000) x 0,1}}=584978,6
\end{aligned}
$$

2. Misal $\mathrm{t}=0$, akan dihitung $\mathrm{Y}_{\mathrm{ij}}{ }^{0}$ sebagai solusi fesibel awal.

a. Dengan mensubstitusi $\mathrm{Y}_{\mathrm{ij}}^{0}$ ke persamaan berikut:

$$
X_{i j}=\sqrt{\frac{2 I_{j} Y_{i j}}{\left(G_{j}+H_{i}\right)}} \quad \forall_{i j}, i j=\mathrm{l}, \mathfrak{Z}, \mathbf{Z}, 3,4
$$


diperoleh nilai untuk $\mathrm{X}_{i j}{ }^{0}$ :

b. Mencari solusi fesibel awal.

\section{Iterasi 1}

- .Menghitung nilai untuk koefisien $\mathrm{A}_{\mathrm{ij}}{ }^{0}$ dengan mensubstitusi $\mathrm{X}_{\mathrm{ij}}{ }^{0} \quad \mathrm{ke}$ persamaan berikut:

$$
\begin{gathered}
A_{i j}=\left(C_{i j}+\frac{I_{j}}{\left(0,001+X_{i j}\right)}\right), \\
\forall_{i}, i=1,2,3, \\
\quad \forall_{j}, j=1,2,3,4
\end{gathered}
$$

- Menentukan solusi fesibel baru $\mathrm{Y}_{\mathrm{ij}}{ }^{1}$ dengan mensubstitusi $\mathrm{A}_{\mathrm{ij}}{ }^{0}$ ke dalam persamaan berikut:

$$
\begin{aligned}
& \text { Minimize } \quad W^{\prime}=1,343540 Y_{11}^{1}+0,7056347 Y_{12}^{1}+0,5377110 Y_{13}^{1} \\
& +0,9935401 Y_{21}^{1}+1,245635 Y_{22}^{1}+1,68771 Y_{23}^{1} \\
& +1,136159 Y_{33}^{1}+0,3331662 Y_{34}^{1} \\
& Y_{12}^{1}+Y_{22}^{1}=9000 \\
& Y_{13}^{1}+Y_{23}^{1}+Y_{33}^{1}=109000 \\
& Y_{34}^{1}=2000 \\
& Y_{11}^{1}+Y_{12}^{1}+Y_{13}^{1}=37000 \\
& Y_{21}^{1}+Y_{22}^{1}+Y_{23}^{1}=37000 \\
& Y_{33}^{1}+Y_{34}^{1}=58000
\end{aligned}
$$

Persamaan diatas diselesaikan menggunakan software LINGO dan diperoleh solusinya yaitu $\mathrm{Y}_{\mathrm{ij}}{ }^{1}$.

- Menghitung $\mathrm{X}_{\mathrm{ij}}{ }^{1}$ dengan mensubstitusi $\mathrm{Y}_{\mathrm{ij}}{ }^{1}$.

- Dengan mensubstitusi $\mathrm{Z}_{\mathrm{i}}, \mathrm{X}_{\mathrm{ij}}{ }^{1}, \mathrm{Y}_{\mathrm{ij}}{ }^{1}, \mathrm{C}_{\mathrm{ij}}$, $\mathrm{S}_{\mathrm{i}}, \mathrm{K}_{\mathrm{i}}, \mathrm{H}_{\mathrm{i}}, \mathrm{P}_{\mathrm{i}}, \mathrm{I}_{\mathrm{j}}, \mathrm{G}_{\mathrm{j}}$, dan $\mathrm{D}_{\mathrm{j}}$ kedalam persaman (4.2.1) diperoleh $\mathrm{W}^{1}$ adalah:

$$
\begin{aligned}
& W^{1}={ }_{i=1}^{m}\left(r_{i} S_{i}+\frac{z_{i}}{2} 1 \frac{S_{i}}{P_{i}} \div H_{i}+\right. \\
&\left.\frac{S_{i}}{z_{i}} K_{i}+\frac{H_{i}}{2}{ }_{j=1}^{n} X_{i j}^{1}\right)+{ }_{i=1}^{m}{ }_{j=1}^{n} C_{i j} Y_{i j}^{1}+ \\
& m \quad{ }^{n}\left(\frac{X_{i j}^{1}}{2} G_{j}+\frac{Y_{i j}^{1}}{\left(0,001+X_{i j}^{1}\right)} I_{j}\right) \\
&{ }_{i=1}^{1} \quad j_{j=1}
\end{aligned}
$$$$
=782394
$$

c. Karena diperoleh nilai $\mathrm{Y}_{\mathrm{ij}}{ }^{1} \neq \mathrm{Y}_{\mathrm{ij}}^{0}$, maka harus kembali ke langkah no $2 \mathrm{~b}$, sehingga menjadi penghitungan untuk iterasi 2.

\section{Iterasi 2}

- Menghitung nilai untuk koefisien $\mathrm{A}_{\mathrm{ij}}{ }^{1}$ dengan mensubstitusi $\mathrm{X}_{\mathrm{ij}}{ }^{1}$.

- Menentukan solusi fesibel baru $\mathrm{Y}_{\mathrm{ij}}^{2}$ dengan mensubstitusi $\mathrm{A}_{\mathrm{ij}}{ }^{1}$ ke dalam persamaan:

$$
\begin{array}{ll}
\text { subject to }: & Y_{11}{ }^{2}+Y_{21}{ }^{2}=12000 \\
& Y_{12}{ }^{2}+Y_{22}{ }^{2}=9000 \\
& Y_{13}{ }^{2}+Y_{23}{ }^{2}+Y_{33}{ }^{2}=109000 \\
& Y_{34}{ }^{2}=2000 \\
& Y_{11}{ }^{2}+Y_{12}{ }^{2}+Y_{13}{ }^{2}=37000 \\
& Y_{21}{ }^{2}+Y_{22}{ }^{2}+Y_{23}{ }^{2}=37000 \\
& Y_{33}{ }^{2}+Y_{34}{ }^{2}=58000
\end{array}
$$$$
\text { Minimaze } \quad W^{\prime}=20001,33 Y_{11}{ }^{2}+20000,69 Y_{12}{ }^{2}+0,5377110 Y_{13}{ }^{2}
$$$$
+0,9935401 Y_{21}{ }^{2}+1,245635 Y_{22}{ }^{2}+1,691726 Y_{23}{ }^{2}
$$$$
+1,136159 Y_{33}{ }^{2}+0,3331662 Y_{34}{ }^{2}
$$

Untuk menyelesaikan persamaan diatas langsung digunakan software LINGO. Dan diperoleh solusi untuk $\mathrm{Y}_{\mathrm{ij}}^{2}$.

- Menghitung $\mathrm{X}_{\mathrm{ij}}^{2}$ dengan mensubstitusi $\mathrm{Y}_{\mathrm{ij}}^{2}$.

- Diperoleh fungsi objektif yang baru $\mathrm{W}^{2}$ dengan mensubstitusi $\mathrm{Z}_{\mathrm{i}}, \mathrm{X}_{\mathrm{ij}}{ }^{2}, \mathrm{Y}_{\mathrm{ij}}{ }^{2}, \mathrm{C}_{\mathrm{ij}}, \mathrm{Si}$, $\mathrm{K}_{\mathrm{i}}, \mathrm{H}_{\mathrm{i}}, \mathrm{P}_{\mathrm{i}}, \mathrm{I}_{\mathrm{j}}, \mathrm{G}_{\mathrm{j}}$, dan $\mathrm{D}_{\mathrm{j}}$ ke persamaan:

$$
\begin{aligned}
& W^{2}={ }_{i=1}^{m} r_{i} S_{i}+\frac{z_{i}}{2} 1 \frac{S_{i}}{P_{i}} \div H_{i}+\frac{S_{i}}{z_{i}} K_{i}+\frac{H_{i}}{2}{ }_{j=1}^{n} X_{i j}^{2} \dot{\doteqdot}+ \\
& { }_{i=1}^{m}{ }_{j=1}^{n} C_{i j} Y_{i j}^{2}+{ }_{i=1}^{m}{ }_{j=1}^{n} \frac{X_{i j}^{2}}{2} G_{j}+\frac{Y_{i j}^{2}}{\left(0,001+X_{i j}^{2}\right)} I_{j} \dot{\doteqdot} \\
& =782394
\end{aligned}
$$

Karena diperoleh nilai $\mathrm{Y}_{\mathrm{ij}}{ }^{2}=\mathrm{Y}_{\mathrm{ij}}{ }^{1}$ maka stop iterasi. $\mathrm{W}^{*}=\operatorname{minimum}\left[\mathrm{W}^{\mathrm{t}+1}\right]=\$ 782394$.

Dengan menggunakan metode konvensional, biaya yang harus dikeluarkan oleh perusahaan sebesar \$782504,5 sedangkan jika menggunakan metode heuristik (Julian Benjamin, 1989) diperoleh total biaya adalah $\$ 782394,0$. Sehingga perusahaan dapat menghemat biaya sebesar $\$ 110,5$. 


\section{KESIMPULAN}

Setelah dilakukan perhitungan dengan menyelesaikan sebuah contoh kasus, dapat disimpulkan bahwa proses pencarian solusi menggunakan metode Optimasi Simultan dengan Heuristik dapat menghasilkan total biaya produksi, transportasi dan inventory lebih minimum dibandingkan menggunakan Metode Optimasi Konvensional.

Diperoleh jumlah produksi barang dan jumlah pengiriman barang pertahunnya optimum, dengan kata lain jumlah produksi memenuhi permintaan konsumen.

\section{SARAN}

Dalam proses pencarian solusi pada sistem multi source dan multi sink diberikan algoritma yang cukup rumit, sehingga dengan menambahkan aplikasi pemrograman yang lebih baik akan sangat membantu dalam perhitungan.

\section{DAFTAR PUSTAKA}

Benjamin, J. 1989. An Analysis of Inventory and Transportation Costs in a Constrained Network: North Carolina: A\&T State University.

Imam, K. 2003. Manajemen Persediaan: Fakultas Ekonomi Universitas Jember.

(di dowload pada 1 Maret 2008). rul2a@yahoo.com

Subagyo, P. dkk. 1992. Dasar-Dasar Operation Research, Edisi Kedua. Yogyakarta: penerbit BPFE.

Winston, W. L., 1994, Operations Research Applications and Algorithms, edisi ketiga, International Thomson Publisher, California. 